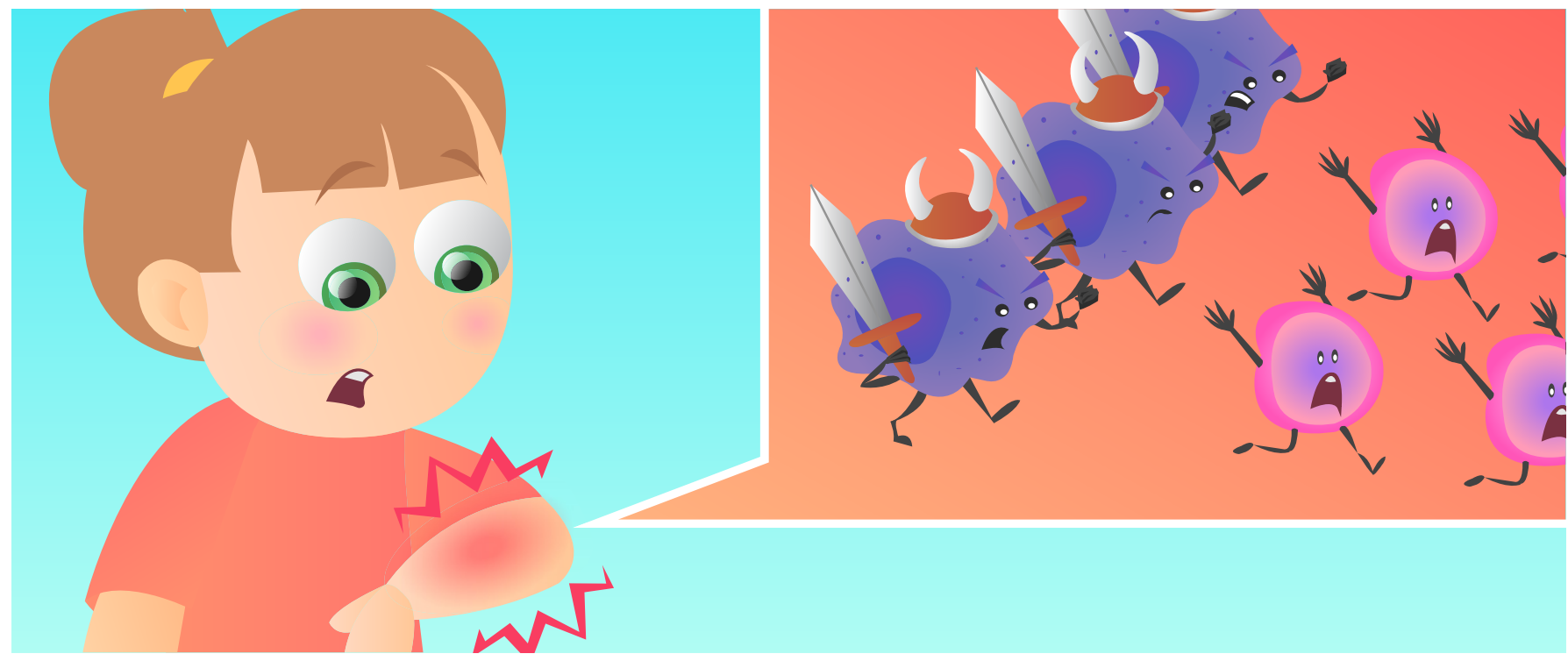

\title{
AUTOIMMUNITY: WHY THE BODY ATTACKS ITSELF
}

\section{Ryan R. Davis and Thomas Hollis*}

Department of Biochemistry, Wake Forest School of Medicine, Winston-Salem, NC, USA

\section{REVIEWED BY:}

HOLYROOD

SECONDARY

$S C H O O L$

9-10 YEARS OLD

\section{MACROPHAGE}

A type of cell

(phagocyte) that eats

dying or infected cells.
The human body is made up of 37 trillion cells and billions of these die every single day. The body has special cells, called macrophages, which consume dying cells to prevent them from building up in your body. Macrophages are also able to eat any cell that is infected by a bacterium or virus. This helps your body to remain as healthy as possible. Sometimes, the macrophages are given the wrong signals and they attack healthy cells. When this happens, your body develops an allergic reaction or inflammation that can lead to something called autoimmunity.

\section{MACROPHAGES ARE HOUSEKEEPERS}

The human body is very complex. It is composed of 37 trillion $(37,000,000,000,000)$ cells. If you were to line up every cell in the human body, the line of cells would stretch a little farther than the distance from the Earth to the moon! Every single day approximately 50 billion $(50,000,000,000)$ cells in the human body die as a normal part of biology. These cells need to be removed to keep the body healthy. The body has special cells, called phagocytes, which eat, or phagocytose, these dying cells and have "housekeeping" roles to make sure that debris is removed. One common type of phagocyte is the macrophage, which in Greek means "Big Eater." When cells are dying, 
PHOSPHATIDYL-

\section{SERINE}

A chemical signal used to call for macrophages to eat a dying cell.

\section{PATHOGENS}

Bacteria or viruses that cause an infection in human cells.

\section{FIGURE 1}

A healthy cell is infected by a virus (purple), which causes phosphatidylserine (red) to be displayed on the surface of the cell, which then recruits macrophages (green) to phagocytose the infected cell. they send out an "eat me" signal, a chemical known as phosphatidylserine, which alerts macrophages and them to phagocytose the dying cells. The macrophages then "chew up" the dying cells using many different digestive proteins, kind of like those in our stomachs. Sometimes, these macrophages can attack our own bodies by consuming cells that are not dying. But, this is not always a bad thing.

\section{MACROPHAGES HELP PREVENT ILLNESS}

Our immune systems work to protect us from illness by recognizing foreign molecules, like those on bacteria or viruses, while not reacting to our own molecules. Bacteria and viruses that cause infection are known as pathogens. When your cells are infected by a pathogen, the pathogen will start to reproduce by making copies of its DNA or RNA (cellular instructions) and will also produce a lot of molecules that fight defense mechanisms of your immune system (Figure 1) [1]. The pathogen's DNA and the molecules it produces are foreign to our human cells and, therefore, act as a "danger" signal indicating that something is wrong with the infected cell. This danger signal causes phosphatidylserine to be exposed on the surface of the infected cell to attract macrophages. After macrophages arrive at the infected cell and phagocytose it, they present pieces of the pathogen, known as antigens, to other immune cells, so that the immune system can create a memory of that specific pathogen. If the infected cells are not phagocytosed by macrophages, then more cells, or even the whole organ, can become infected with the pathogen. When the infected cell is chewed up by macrophages, the bacteria or viruses cannot survive or reproduce they die along with the infected cell. This stops the infection and keeps the body healthy. Figure 2 shows a macrophage that has phagocytosed four

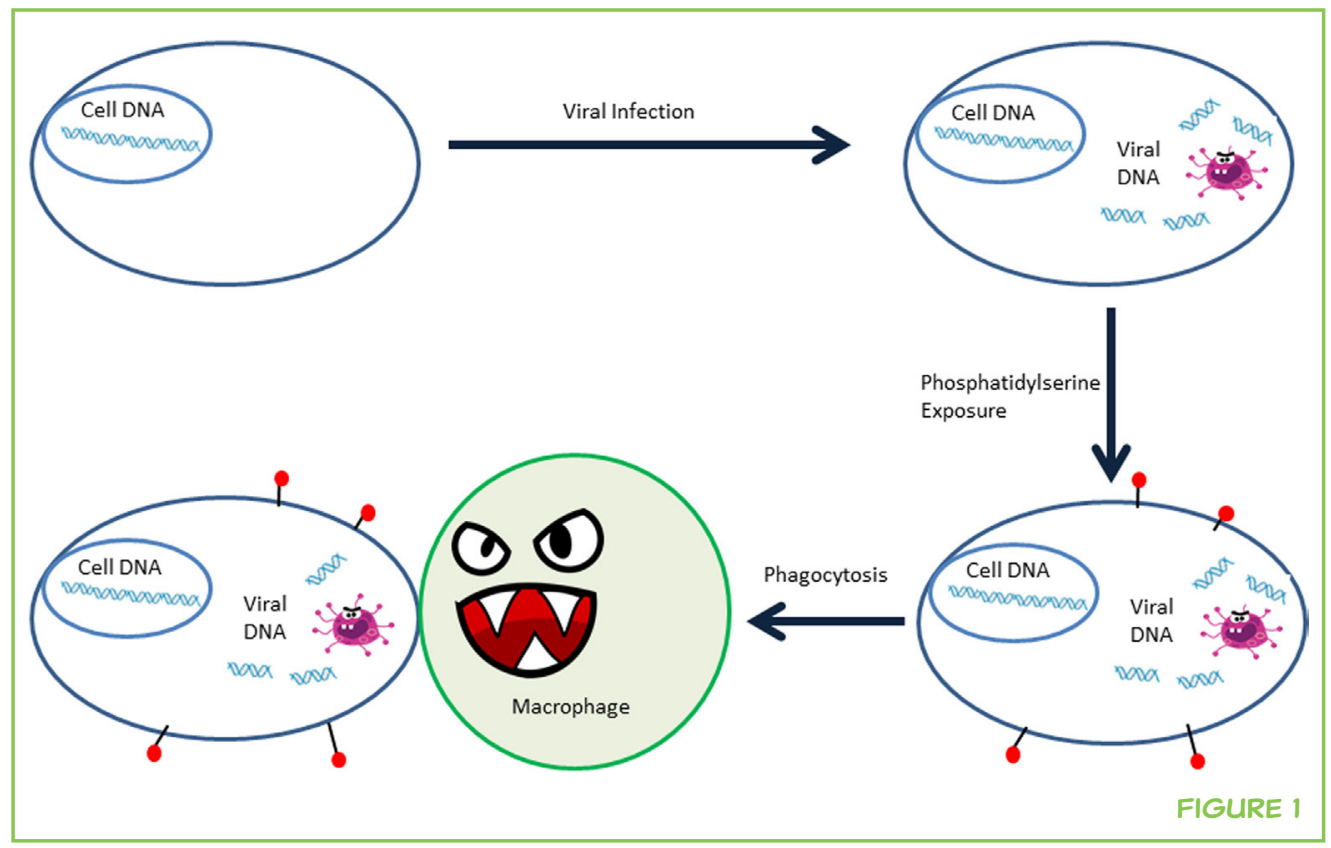




\section{FIGURE 2}

An electron microscope image showing a macrophage phagocytosing four dying cells (black blobs inside of the macrophage) [2].

\section{TREX1}

A protein that chews up DNA.

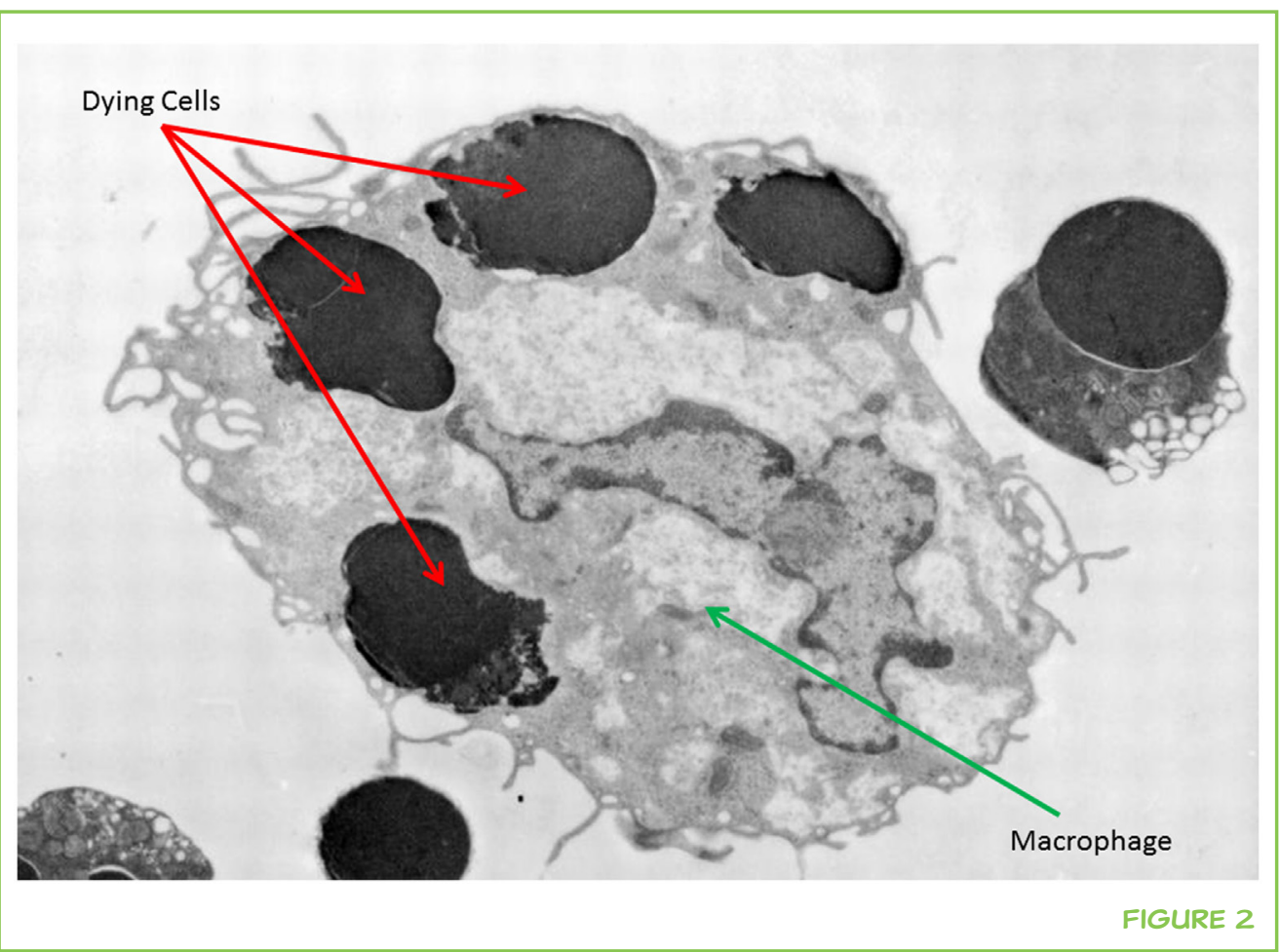

dying cells. This picture was taken by a very powerful microscope called an electron microscope.

\section{DNA PIECES CAN ACTIVATE MACROPHAGES}

In our cells, the DNA is contained within the nucleus, or control center, of the cell. When DNA is found outside the nucleus, it might signal that the cell has been infected by a bacterium or virus. When this happens, the cell sends out signals to tell the cells of the immune system that there is a problem. Many viruses infect a cell and copy their DNA, so that they can insert their DNA into the cell's DNA to hide it from the immune system. But, the virus is very messy when it copies its DNA and leaves many small DNA pieces floating around. If the cell senses these DNA pieces, then the cell calls for macrophages to phagocytose it before the virus' DNA can get into the cell's DNA. However, viruses have evolved to be very sneaky. The virus uses special proteins, like one called TREX1, to chew up small pieces of DNA outside the nucleus that could attract macrophages [3]. While the virus makes a mess with its DNA, TREX1 chews up the DNA, so that the macrophages do not attack the infected cell. This makes the cell seem healthy even though it is infected and allows the virus to keep growing. But, if TREX1 stops working then the pieces of DNA start to pile up and the cell gets really sick. The macrophages will then start attacking this sick cell even if it is not infected and this can cause inflammation.

\section{THE IMMUNE SYSTEM CAN ALSO CAUSE ILLNESS}

Sometimes, after the "danger" signal has passed, the cells do not remove the "eat me" signal. When this happens, the immune system still thinks the cells 
AUTOIMMUNITY

An illness caused by macrophages attacking healthy cells.
IMMUNOSUPPRESSANTS

Drugs used to slow down the immune system from attacking healthy cells.

are infected and will continue to attack them. Other times, healthy cells will present certain "normal" antigens to the immune system in such a way that the immune system gets activated even though there is not a "danger" signal inside the host cell. When this happens, the macrophages do not know there is not a real threat and will attack the healthy cell anyway. This response can cause allergic reactions or a condition called autoimmunity. Autoimmunity is the process in which the immune system attacks your body. Autoimmunity causes inflammation (swelling) and pain. Autoimmunity can be present through the entire body or it can be contained within one organ. There are more than the 80 different illnesses caused by autoimmunity, such as lupus, rheumatoid arthritis, and Crohn's disease. Autoimmunity affects millions of Americans, and women are especially susceptible with, $75 \%$ of all autoimmune patients being women. So, how can we treat autoimmunity?

\section{TREATMENTS FOR AUTOIMMUNITY}

Autoimmunity is a complicated problem because each different autoimmune disease involves macrophages attacking different cells in different areas in their body. For example, in myocarditis, the immune system attacks the heart, and in lupus nephritis, the kidneys are attacked. Because autoimmunity is so complicated, most current treatments for autoimmune diseases only treat the symptoms of the disease. The treatments make the patient feel better, but they do not actually stop the macrophages from attacking the body. Some of the most common treatments for people who are really sick from autoimmune diseases are drugs called immunosuppressants. These drugs suppress, or slow down, the immune system. Although immunosuppressants are good for making the patient feel better from their disease, these drugs also increases the chance of that person getting a lot sicker from other bacteria or viruses, like the common cold, because the immune system does not work as well when these drugs are taken. Another type of drug given to patients with autoimmune diseases is a drug that decreases the patient's swelling and inflammation. Such drugs are called anti-inflammatory drugs. Some anti-inflammatory drugs are also used as headache medicines. Anti-inflammatory drugs can make the patient feel more comfortable by removing some of their pain.

\section{SUMMARY}

The body is composed of trillions of cells and when these cells are sick and dying they need to be removed. Macrophages are one type of cell that consumes the dying or infected cells to maintain a healthy body. Cells in the body can sense when they are infected by a bacterium or virus, because of the presence of foreign molecules produced by the pathogen. The infected cell uses these foreign molecules to call for macrophages to come and phagocytose the infected cell. When the infected cell is digested, the virus and bacterium will also die and will not be able to reproduce and infect other cells. Sometimes, 
the immune system gets an incorrect message, and it attacks cells that are not infected or dying. This causes allergic reactions or autoimmune diseases. Current treatments for autoimmunity only help with the patient's symptoms by decreasing pain or inflammation or by suppressing the immune system. With more research, the scientific and medical fields will be better able to understand and treat autoimmune diseases.

\section{REFERENCES}

1. National Institute of Allergy and Infectious Diseases. 2013. Immune System. Available at: https://www.niaid.nih.gov/research/immune-system-overview

2. Mcllroy, D., Tanaka, M., Sakahira, H., Fukuyama, H., Suzuki, M., Yamamura, K., et al. 2000. An auxiliary mode of apoptotic DNA fragmentation provided by phagocytes. Genes Dev. 14:549-58. doi:10.1101/gad.14.5.549

3. Bailey, S. L., Harvey, S., Perrino, F. W., and Hollis, T. 2012. Defects in DNA degradation revealed in crystal structures of TREX1 exonuclease mutations linked to autoimmune disease. DNA Repair (Amst.) 11(1):65-73. doi:10.1016/j.dnarep. 2011.10.007

SUBMITTED: 17 February 2016; ACCEPTED: 14 September 2016; PUBLISHED ONLINE: 29 September 2016.

EDITED BY: Pasquale Maffia, University of Glasgow, UK

CITATION: Davis RR and Hollis T (2016) Autoimmunity: Why the Body Attacks Itself. Front. Young Minds 4:23. doi:10.3389/frym.2016.00023

CONFLICT OF INTEREST STATEMENT: The authors declare that the research was conducted in the absence of any commercial or financial relationships that could be construed as a potential conflict of interest.

COPYRIGHT ( 2016 Davis and Hollis. This is an open-access article distributed under the terms of the Creative Commons Attribution License (CC BY). The use, distribution and reproduction in other forums is permitted, provided the original author(s) or licensor are credited and that the original publication in this journal is cited, in accordance with accepted academic practice. No use, distribution or reproduction is permitted which does not comply with these terms.

\section{REVIEWED BY}

\section{HOLYROOD SECONDARY SCHOOL, 9-10 YEARS OLD}

Our school is very diverse. It includes many students from lots of different countries. The multicultural approach of our classes values, everyone's opinions, and points of view despite having various experiences. Subjects like Biology teach us that diversity is just one of the creations and must be preserved as well as respected. It is particular interesting how we can relate to the Biology topics applying our knowledge in every day life and experiences. 


\section{AUTHORS}

\section{RYAN R. DAVIS}

As a scientist, I study the role of DNA in autoimmunity, and how specific enzymes degrade this DNA to keep the body healthy. I am interested in finding out how the DNA is disposed in dying cells to prevent inflammatory reactions that cause illness. When I am not in the lab, I enjoy reading, being outdoors, and traveling with my wife.

\section{THOMAS HOLLIS}

I am a Biochemist interested in understanding how proteins interact with DNA to carry out biological processes. Protein-DNA interactions are necessary for normal cell growth and division, and can also contribute to diseases such as cancer and autoimmune disease. By understanding this biology, my hope is that we can eventually develop treatments for diseases caused by improper protein-DNA interactions. *thollis@wakehealth.edu 